\title{
Anticonflict Action of Tandospirone in a Modified Geller-Seifter Conflict Test in Rats
}

\author{
Hiroshi Shimizu, Yoshino Kumasaka, Hiroyasu Tanaka, \\ Akira Hirose and Mitsutaka Nakamura \\ Research Laboratories, Sumitomo Pharmaceuticals Co., Lid., \\ 3-1-98, Kasugadenaka, Konohana-ku, Osaka 554, Japan \\ Received October 5, 1991 Accepted December 17, 1991
}

\begin{abstract}
Tandospirone is a novel non-benzodiazepine compound possessing potent anxiolytic properties in a water lick conflict paradigm in rats and a high affinity for central $5-\mathrm{HT}_{1 \mathrm{~A}}$ receptors. In the present study, tandospirone was evaluated for anxiolytic activity in a modified Geller-Seifter conflict paradigm in rats. Tandospirone produced significant increases in the punished responding at doses of $1.25,2.5$ and 5.0 $\mathrm{mg} / \mathrm{kg}$, i.p. or $20 \mathrm{mg} / \mathrm{kg}$, p.o., although it decreased unpunished responding at doses of 2.5 and $5.0 \mathrm{mg} / \mathrm{kg}$, i.p. or $20 \mathrm{mg} / \mathrm{kg}$, p.o. Likewise, diazepam was also effective after i.p.-administration in this test, and its minimum effective dose was slightly higher than that of tandospirone. This suggests that tandospirone might be as effective in the treatment of anxiety as diazepam. The anticonflict action of tandospirone was not inhibited by Ro-15-1788, a benzodiazepine antagonist, although that of diazepam was completely inhibited. 8-OH-DPAT, a full agonist of 5- $\mathrm{HT}_{1 \mathrm{~A}}$ receptors, was also effective in this test with a high potency. Therefore, the possibility exists that the anticonflict action of tandospirone is related to its agonist action on 5-HT $\mathrm{IA}_{\mathrm{A}}$ receptors, not on benzodiazepine receptors.
\end{abstract}

It has been long suggested that the central serotonin (5-HT) system may be involved in the modulation of anxiety (1). The recent development of compounds that interact in a specific manner with part of the 5-HT system has provided evidence that there are several subtypes of central 5-HT receptors: $5-\mathrm{HT}_{1}, 5$ $\mathrm{HT}_{2}, 5-\mathrm{HT}_{3}$ and $5-\mathrm{HT}_{4}$ receptors $(2,3)$, and these compounds have provided a means to elucidate the role of 5-HT in anxiety in more detail. Particularly, recent attention has been focused on 5- $\mathrm{HT}_{\mathrm{IA}}$ receptors, a subtype of 5 $\mathrm{HT}_{1}$ receptors, hecause of their high densities in the hippocampus and other parts of the limbic system that may be involved in the control of anxiety states (4). We previously reported that tandospirone $(3 \mathrm{a} \alpha, 4 \beta, 7 \beta, 7 \mathrm{a} \alpha$-hexahydro2 -(4-(4-(2-pyrimidinyl)-1-piperazinyl)-butyl)- 4,7methano- $1 H$-isoindole-1,3(2H)-dione dihydrogen citrate) is a non-benzodiazepine compound possessing both potent anxiolytic properties in animal models (5) and a high affinity for $5-\mathrm{HT}_{1 \mathrm{~A}}$ receptors (6). Therefore, this compound may be useful not only as a new therapeutic drug for treating anxiety, but also a valuable tool for basic research on the role of 5-HT in anxiety.

In the meantime, a number of animal models of anxiety have been developed to predict the clinical potencies of drugs (7). The GellerSeifter conflict test (8) is one of the most reliable tests for anxiolytic activity, bccause there 
is a good correlation between the minimum effective doses of anxiolytics in this test and their clinical doses (9). In the present study, we evaluated the anxiolytic activity of tandospirone in rats with a modified Geller-Seifter conflict test, comparing it with that of diazepam. Furthermore, we also studied both the effect of a benzodiazepine antagonist on the anticonflict action of tandospirone and the anxiolytic activity of 8 -hydroxy-2-(di-n-propylamino)tetralin (8-OH-DPAT), a selective 5$\mathrm{HT}_{1 \mathrm{~A}}$ agonist.

\section{MATERIALS AND METHODS}

\section{Animals}

Male Sprague-Dawley rats $(270-320 \mathrm{~g})$ were kept on a controlled light-dark cycle (lights on $0800-2000$ hours) in a room with constant temperature $\left(24 \pm 1{ }^{\circ} \mathrm{C}\right)$ and humidity $(55 \pm 5 \%)$. These animals were gradually reduced to $80 \%$ of normal body weight and then given training as described below. They were maintained at this level (approximately $80-$ $85 \%$ of the free-feeding weight) by limited feeding after each experimental session.

\section{Apparatus}

A conventional Skinner box $(30 \times 30 \times$ $27.5 \mathrm{~cm}$; Medical Agent Co., Ltd.) containing a response lever, an automatic feeder for the delivery of a solid food reward $(50 \mathrm{mg})$, an electrified-grid floor, and a small speaker and a red lamp for the presentation of auditory and visual stimulus, respectively, was used. This box was enclosed by a sound-resistant, ventilated chamber, and this chamber was set in a sound-resistant room. Programming and recording of the experiment were automated, and the intensity of foot-shock punishment was adjusted for each rat during training to achieve an optimal degree of suppression (range: $0.5-1.3 \mathrm{~mA}, 0.5 \mathrm{sec}$ duration).

\section{Procedure}

The animals were first trained to respond on a fixed-ratio schedule of 20 lever-press rcsponses for each food reinforcement (FR20).
After stable FR20 performance was developed, nonaversive tone $(2 \mathrm{kHz}, 85 \mathrm{~dB})$ and light (14 lux) stimuli of 3-min duration were activated every $15 \mathrm{~min}$ during the 60 -min experimental session. These stimuli signaled that every lever response would be reinforced with food, in contrast to the no-stimulus (unpunished) periods when every 20th response was food reinforced. Conflicts were then induced by punishing all lever responses in the presence of the stimuli (the punished periods) with a scrambled electric shock through the grid floor: thus, the rats were simultaneously rewarded with food and punished with shock for every lever response made in the 3-min punished periods. The daily $60-\mathrm{min} \mathrm{ex}-$ perimental sessions consisted of four 12-min unpunished periods and four 3-min punished periods; and they were conducted at the same time, Monday through Friday, for each rat. The rats that exhibited stable rates of unpunished and punished responding after training for about 4 weeks were used for the drug studies.

\section{Analysis of result}

Unpunished responding was expressed as a percentage of control responses that were made in the unpunished periods on the day before the drug injection for each individual rat. Punished responding was expressed as the number of responses made in the punished periods $(12 \mathrm{~min})$. All results are represented as the mean values \pm S.E.M. obtained from five to ten rats. Drug effects were assessed statistically by comparing the responding after the administration of drugs to the responding after the administration of vehicle using Dunnett's test or Duncan's test.

\section{Drugs}

Tandospirone, 8-OH-DPAT HBr, diazepam and Ro-15-1788 were synthesized at the Sumitomo Pharmaceuticals Co., Ltd. Diazepam and Ro-15-1788 were suspended in an aqueous solution containing $0.5 \%$ methyl cellulose, and the other drugs were dissolved in $0.9 \%$ sterile saline. Injections were given intraperitoneally 
(i.p.), orally (p.o.) or subcutaneously (s.c.) in a constant volume of $5.0 \mathrm{ml} / \mathrm{kg}$. Ro-15-1788 and the other drugs were administered $10 \mathrm{~min}$ and immediately, respectively, prior to testing.

\section{RESULTS}

The introduction of punishment with electric shock markedly reduced the rates of responding during the punished periods. The mean rates of lever pressing in rats treated with the vehicle $(\mathrm{N}=45)$ were $3985.5 \pm 108.0 /$ session (48 $\mathrm{min}$ ) and $1.3 \pm 0.1 / \mathrm{session}(12 \mathrm{~min})$ for the unpunished periods and the punished periods, respectively.

(A) i.p.
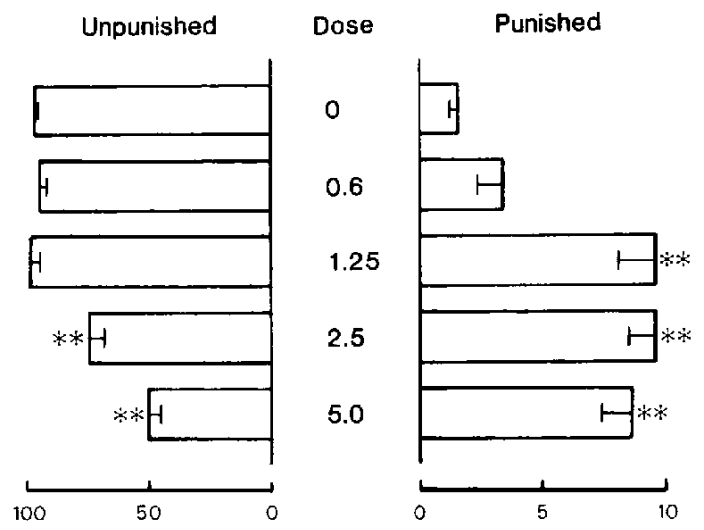

(B) p.o.

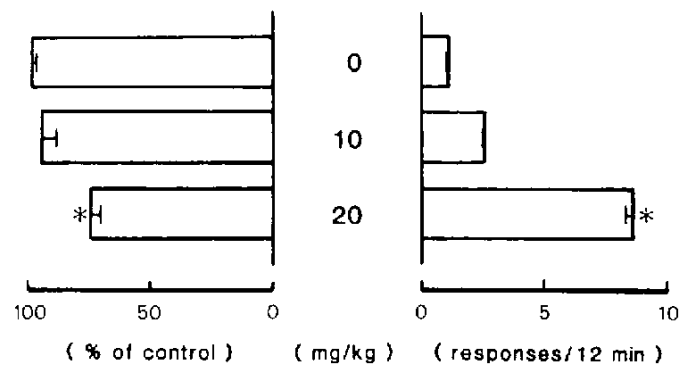

Fig. 1. Effect of tandospirone on unpunished and punished responding in the conflict test. Tandospirone was administered i.p. (A) or p.o. (B) to rats immediately prior to testing. Each value represents the mean \pm S.E.M. obtained from ten rats. Significantly different from the corresponding vehicle-treated groups: ${ }^{*} \mathrm{P}<0.05,{ }^{* *} \mathrm{P}<0.01$ (Dunnett's test).
The effects of tandospironc on lever pressing are shown in Fig. 1. Tandospirone when administered i.p. produced significant increases in punished responding at doses of $1.25,2.5$ and $5.0 \mathrm{mg} / \mathrm{kg}$. Unpunished responding remained stable at doses of up to 1.25 $\mathrm{mg} / \mathrm{kg}$, but was significantly decreased at doses of 2.5 and $5.0 \mathrm{mg} / \mathrm{kg}$ in a dose-dependent manner. Following oral administration, tandospirone also produced a significant increase in punished responding at $20 \mathrm{mg} / \mathrm{kg}$ in spite of a significant decrease in unpunished responding. Figure 2 shows the effects of i.p.administration of diazepam on lever pressing. Likewise, diazepam also produced significant increases in punished responding at doses of 2.5 and $5.0 \mathrm{mg} / \mathrm{kg}$, although it decreased unpunished responding at $5.0 \mathrm{mg} / \mathrm{kg}$. The minimum effective dose of diazepam was slightly higher than that of tandospirone.

Figure 3 shows the effects of Ro-15-1788, a benzodiazepine antagonist, on the anticonflict action of tandospirone and diazepam. Ro-151788 (10 mg/kg, i.p.) significantly reduced punished responding that normally occurs after diazepam $(2.5 \mathrm{mg} / \mathrm{kg}$, i.p. $)$, without affect-

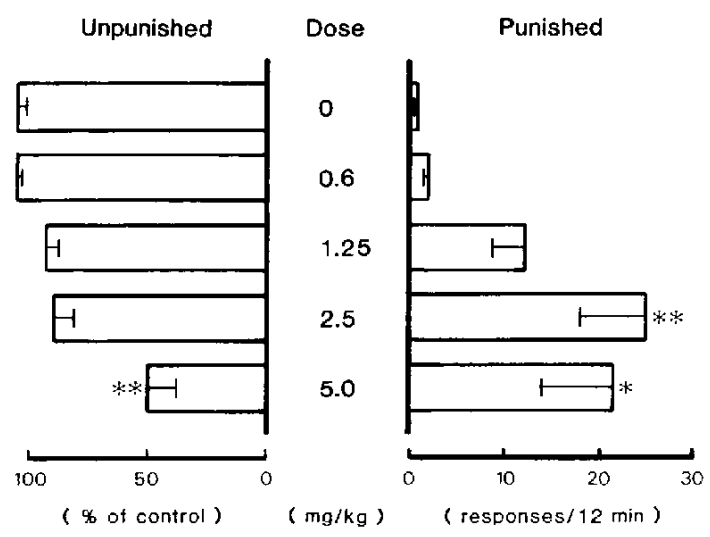

Fig. 2. Effect of diazepam on unpunished and punished responding in the conflict test. Diazepam was administered i.p. to rats immediately prior to testing. Each value represents the mean \pm S.E.M. obtained from eight rats. Significantly different from the corresponding vehicle-treated groups: ${ }^{*} \mathrm{P}<0.05, \quad{ }^{* *} \mathrm{P}<$ 0.01 (Dunnett's test). 
(A) Tandospirone

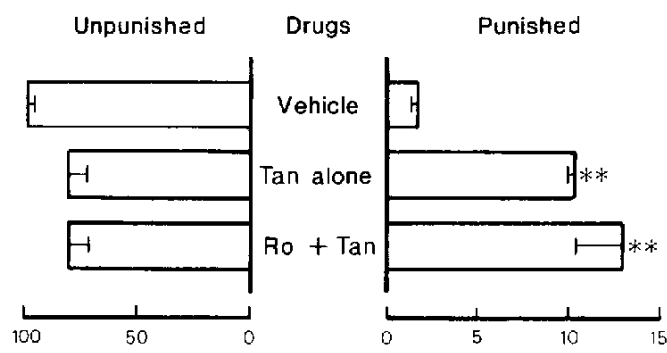

(B) Diazepam

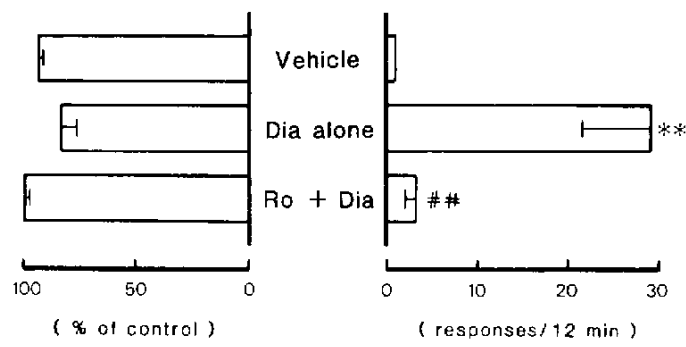

Fig. 3. Effect of Ro-15-1788 on the anticonflict actions of tandospirone (A) and diazepam (B). Ro-151788 (Ro, $10 \mathrm{mg} / \mathrm{kg}$ ) was administered i.p. $10 \mathrm{~min}$ prior to the injection of tandospirone or diazepam. Tandospirone (Tan, $2.5 \mathrm{mg} / \mathrm{kg}$ ) or diazepam (Dia, 2.5 $\mathrm{mg} / \mathrm{kg}$ ) was administered immediately prior to testing. Each value represents the mean \pm S.E.M. obtained from five rats (A) or six rats (B). Significantly different from the corresponding vehicle-treated groups: ${ }^{* *} \mathrm{P}<0.01$ (Duncan's test). Significantly different from the corresponding drug alone groups: \# $\mathrm{P}<$ 0.01 (Duncan's test).

ing unpunished responding. In contrast, this dose of Ro-15-1788 failed to produce any significant changes in punished responding enhanced by tandospirone.

Figure 4 shows the effect of s.c.-administration of 8-OH-DPAT, a $5-\mathbf{H T}_{1 \mathrm{~A}}$ receptor selective agonist, on lever pressing. Punished responding showed an upward trend after 0.05 $\mathrm{mg} / \mathrm{kg}$ of $8-\mathrm{OH}-\mathrm{DPAT}$, but this change was not significant. 8-OH-DPAT at $0.1 \mathrm{mg} / \mathrm{kg}$, however, significantly increased punished responding without affecting unpunished responding.

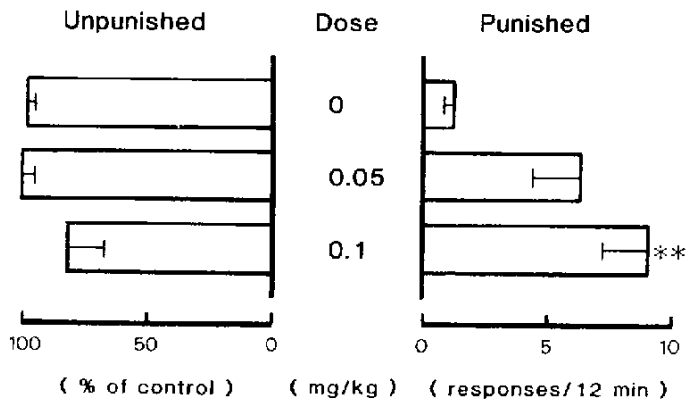

Fig. 4. Effect of 8-OH-DPAT on unpunished and punished responding in the conflict test. 8-OH-DPAT was administered s.c. to rats immediatcly prior to testing. Each value represents the mean \pm S.E.M. obtained from six rats. Significantly different from the corresponding vehicle-treated groups: ${ }^{* *} \mathrm{P}<0.01$ (Dunnett's test).

\section{DISCUSSION}

In the present study, we found that tandospirone, whether administered i.p. or p.o., produced significant increases in punished responding in a modified Geller-Seifter conflict paradigm (main modifications are changing the food reward from a liquid (sweetened condensed milk) to a solid (a pellet of food) and changing the schedule to include an unpunished period from VI-2 min to FR-20) in rats. We also observed that the effect of diazepam in this test was similar to that of tandospirone. These results indicate that tandospirone as well as diazepam can show anticonflict actions in this conflict procedure. Moreover, good agreement of the minimum effective dose of tandospirone in this test with that of diazepam suggests that tandospirone might be as effective in the treatment of anxiety as diazepam. On the other hand, tandospirone as well as diazepam significantly reduced unpunished responding. Lack of muscle relaxant action (5), which diazepam markedly shows, suggests that the mechanism of the decrease in unpunished responding by tandospirone is different from that by diazepam. Since tandospirone produces 5-HT behavioral syndromes such as flat body posture in rats (10), this action of tandospirone may be related to the de- 
crease in unpunished responding.

Recently, there have been many reports evaluating the anxiolytic activities of azapirones, such as buspirone and tandospirone, in conventional animal models of anxiety, but the data were not consistently positive (11). For example, in rat conflict tests, which are the most widely used animal behavioral paradigms for recognizing potential anxiolytic drug activity, some groups, including our own, were able to demonstrate anticonflict activities of azapirones $(5,12-14)$, while others failed to find any positive effects $(15-17)$. Moreover, in the former cases, the efficacies of azapirones were substantially lower than those of benzodiazepines. In the present study, we also found that the magnitude of the tandospironeinduced increase in punished responding was considerably less than that observed with diazepam, although the potency (i.e., the minimum effective dose) of tandospirone was higher than that of diazepam. Conventional conflict tests have been mainly developed in studies of benzodizepines. Since azapirones differ from benzodiazepines not only in chemical structure but also in pharmacological properties $(5,18)$, these tests might be less sensitive to non-benzodiazepines such as azapirones. Therefore, the fine differences in test conditions (e.g., shock intensity, degree of deprivation and conflict schedule conditions) may have led to the inconsistent results previously described.

Tandospirone has no affinity for the benzodiazepine/GABA receptor complex that is thought to mediate the anxiolytic effect of benzodiazepines (6). As was expected from that, Ro-15-1788, a benzodiazepine antagonist, showed no effect on the anticonflict action of tandospirone, though the same dose of Ro-151788 completely inhibited that of diazepam. This result suggests that benzodiazepine receptors do not participate in the mechanism of action of tandospirone. We previously reported that tandospirone binds selectively to central $5-\mathrm{HT}_{1 \mathrm{~A}}$ receptors with a high affinity in binding studies using either membranes or sections of rat brain as receptor preparations of the
CNS $(6,19-21)$. All other azapirones that are clinically effective also bind selectively to 5 $\mathrm{HT}_{1 \mathrm{~A}}$ receptors (22). Moreover, we have also demonstrated that tandospirone acts on 5-

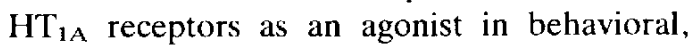
biochemical and electrophysiological studies $(10,19,23-26)$. In the light of these facts, the possibility exists that the agonist action of tandospirone on $5-\mathrm{HT}_{1 \mathrm{~A}}$ receptors, but not benzodiazepine receptors, is related to its conflict effect.

There are several reports showing that two azapirones, buspirone and ipsapirone, act as partial agonists with agonist activity predominating on $5-\mathrm{HT}_{1 \mathrm{~A}}$ receptors $(27-29)$. Moreover, Moser et al. (30) have reported that a compound which acts primarily as an antagonist on $5-\mathrm{HT}_{1 \mathrm{~A}}$ receptors showed anticonflict action. Then, we studied the effect of $8-\mathrm{OH}$ DPAT, a full agonist of 5-HT $\mathrm{HA}_{\mathrm{A}}$ receptors, using this conflict test to determine which action, agonist or antagonist action, is more important for producing the anticonflict effect. 8OH-DPAT clearly produced strong anticonflict action. The minimum effective dose of 8 OH-DPAT in this test was nearly equal to that obtained by Engel et al. (31) in a modified Vogel's conflict test in rats. We have reported that tandospirone inhibits forskolinstimulated adenylate cyclase in the rat hippocampus via $5-\mathrm{HT}_{1 \mathrm{~A}}$ receptors (24). In that study, we also found that the maximal inhibition by tandospirone was nearly equal to those by 8-OH-DPAT and 5-HT. This indicates that tandospirone is nearly a full agonist of $5-\mathrm{HT}_{1 \mathrm{~A}}$ receptors. Moreover, we have found that spiroperidol (a nonselective $5-\mathrm{HT}_{1 \mathrm{~A}}$ antagonist), but not haloperidol ( $\mathrm{D}_{2}$ antagonist) or ketanserin (5- $\mathrm{HT}_{2}$ antagonist), inhibits significantly the anticonflict action of tandospirone in Vogel's conflict test (H. Shimizu et al., unpublished data). Therefore, these results suggest that the anticonflict effect of tandospirone in this model may result from its agonist action on $5-\mathrm{HT}_{1 \mathrm{~A}}$ receptors.

In summary, we found that tandospirone showed anticonflict action in a modified Geller-Seifter conflict paradigm in rats with 
slightly lower minimum effective dose than diazepam, indicating its efficacy in the treatment of anxiety in humans. However, it was suggested that the anticonflict action of tandospirone, unlike that of diazepam, was not mediated by benzodiazepine receptors. Since a 5 $\mathrm{HT}_{1 \mathrm{~A}}$ selective agonist (8-OH-DPAT) also produced potent anticonflict action in this model, the possibility exists that the agonist action of tandospirone on $5-\mathrm{HT}_{1 \mathrm{~A}}$ receptors, but not that on binzodiazepine receptors, is related to its conflict effect. Further studies on this point are in progress.

\section{REFERENCES}

1 Stein, L., Wise, C.D. and Belluzzi, J.D.: Neuropharmacology of reward and punishment. In Handbook of Psychopharmacology, Edited by Iversen, L.L., Iversen, S.D. and Snyder, S.H., Vol. 8, p. 25-53, Plenum Press, New York (1977)

2 Bradley, P.B., Engel, G., Feniuk, W., Fozard, J.R., Humphrey, P.P.A., Middlemiss, D.N. et al.: Proposals for the classification and nomenclature of functional receptors for 5-hydroxytryptamine. Neuropharmacology 25, 563-576 (1986)

3 Dumuis, A., Sebben, M. and Bockaert, J.: The gastrointestinal prokinetic benzamide derivatives are agonists at the non-classical 5-HT receptor (5$\mathrm{HT}_{4}$ ) positively coupled to adenylate cyclase in neurons. Naunyn Schmiedebergs Arch. Pharmacol. 340, 403-410 (1989)

4 Gozlan, H., El Mestikawy, S., Pichat, L., Glowinski, J, and Hamon, M.: Identification of presynaptic serotonin autoreceptors using a new ligand: ${ }^{3}$ H-PAT. Nature 305, 140-142 (1983)

5 Shimizu, H., Hirose, A., Tatsuno, T., Nakamura. M. and Katsube, J.: Pharmacological properties of SM-3997: a new anxioselective anxiolytic candidate. Japan. J. Pharmacol. 45, 493-500 (1987)

6 Shimizu, H., Karai, N., Hirose, A., Tatsuno, T., Tanaka, H., Kumasaka, Y. et al.: Interaction of SM-3997 with serotonin receptors in rat brain. Japan. J. Pharmacol. 46, 311-314 (1988)

7 File, S.E.: Models of anxiety. Br. J. Clin. Pract. 39, Supp. 15-20 (1985)

8 Geller, I. and Seifter, J.: The effects of meprobamate, barbiturates, $d$-amphetamine and promazine on experimentally induced conflict in the rat. Psychopharmacology (Berlin) 1, $482-492$ (1960)

9 Cook, L. and Davidson, A.B.: Effects of behaviorally active drugs in a conflict-punishment procedurc in rats. $\boldsymbol{l} n$ The Benzodiazepines, p. 327 345, Raven Press, New York (1973)

10 Shimizu, H., Hirose, A., Karai, N., Tatsuno, T., Nakamura, M. and Katsube, J.: The mechanism of the pharmacological action of SM-3997: A new anxioselective anxiolytic agent. Japan. J. Pharmacol. 40, Supp. 191P (1986)

11 Chopin, P. and Breley, M.: Animal models of anxiety: the effect of compounds that modify 5-HT neurotransmission. TIPS 8, 383-388 (1987)

12 Pich, E.M. and Samanin, R.: Disinhibitory effects of buspirone and low doses of sulpiride and haloperidol in two experimental anxiety models in rats: possible role of dopamine. Psychopharmacology (Berlin) 89, 125 - 130 (1986)

13 McCloskey, T.C., Paul, B.K. and Commissaris, R.L.: Buspirone effects in an animal conflict procedure: comparixon with diazepam and phenobarbital. Pharmacol. Biochem. Behav. 27, 171-175 (1987)

14 Young, R., Urbancic, A., Emrey, T.A., Hall, P.C. and Metcalf, G.: Behavioral effects of several new anxiolytics and putative anxiolytics. Eur. J. Pharmacol. 143, 361 - 371 (1987)

15 Gardner, S.R.: Recent developments in 5HT-related pharmacology of animal models of anxicty. Pharmacol. Biochem. Behav. 24, 1479-1485 (1986)

16 Budhram, P., Deacon, R. and Gardner, C.R.: Some putative non-sedating anxiolytics in a conditioned licking conflict. Br. J. Pharmacol. 88, Supp. 331P (1986)

17 Goldberg, M.E., Salama, A.I., Patel, J.B. and Malick, J.B.: Novel non-benzodiazepine anxiolytics. Neuropharmacology 22, 1499-1504 (1983)

18 Riblet, L.A., Taylor, D.P., Eison, M.S. and Stanton, H.C.: Pharmacology and neurochemistry of buspirone. J. Clin. Psychiatry 43, 11-16 (1982)

19 Shimizu, H., Tatsuno, T., Hirose, A., Tanaka, H., Kumasaka, Y. and Nakamura, M.: Characterization of the putative anxiolytic SM-3997 recognition sites in rat brain. Life Sci. 42, 2419-2427 (1988)

20 Tanaka, H., Shimizu, H., Tatsuno, T., Hirose, A., Kumasaka, Y. and Nakamura, M.: Autoradiographic evidence for the interaction of SM3997 with $5-\mathrm{HT}_{\mathrm{AA}}$ receptors in the rat brain. Japan. J. Pharmacol. 52, 504-507 (1990)

21 Tanaka, H., Shimizu, H., Kumasaka, Y., Hirose, A., Tatsuno, T. and Nakamura, M.: Autoradiographic localization and pharmacological characterization of ${ }^{3} \mathrm{H}$-tandospirone binding sites in the rat brain. Brain Res. 546, $181-189$ (1991)

22 Hamik, A., Oksenberg, K., Fischette, C. and 
Peroutka, S.J.: Analysis of tandospirone (SM3997) interactions with neurotransmitter receptor binding sites. Biol. Psychiatry 28, $99-109$ (1990)

23 Tatsuno, T., Shimizu, H., Hirose, A., Tanaka, H., Kumasaka, Y. and Nakamura, M.: Effects of putative anxiolytic SM-3997 on the central monoaminergic systems. Pharmacol. Biochem. Behav. 32, $1049-1055$ (1989)

24 Shimizu, H., Tatsuno, T., Hirose, A., Tanaka, H., Kumasaka, Y. and Nakamura, M.: The pharmacological properties of SM-3997: a comparative study with some $5-\mathrm{HT}_{1 \wedge}$ related anxiolytics. Japan. J. Pharmacol. 49, Supp. 227P (1989)

25 Hirose, A., Sasa, M., Akaikc, A. and Takaori, S.: Inhibition of the hippocampal $\mathrm{CA}_{1}$ neurons by 5 hydroxytryptamine, derived from the dorsal raphe nucleus and the 5-hydroxytryptamine ${ }_{1 \mathrm{~A}}$ agonist SM-3997. Neuropharmacology 29, 93-101 (1990)

26 Hirose, A., Tsuji, R., Shimizu, H., Tatsuno, T. Tanaka, H., Kumasaka, Y. et al.: Inhibition by 8 hydroxy-2-(di-n-propylamino)tetralin and SM-3997, a novel anxiolytic drug, of the hippocampal rhythmical slow activity mediated by 5-hydroxytryptamine $_{1 \mathrm{~A}}$ receptors. Naunyn Schmiedebergs Arch. Pharmacol. 341, 8-13 (1990)

27 Andrade, R. and Nicoll, R.A.: Novel anxiolytics discriminate between postsynaptic serotonin receptors mediating different physiological responses on single neurons of the rat hippocampus. Naunyn Schmiedebergs Arch. Pharmacol. 336, 5-10 (1987)

28 Smith, L.M. and Peroutka, S.J.: Differential effects of 5-hydroxytryptamine ${ }_{1 \mathrm{~A}}$ selective drugs on the 5-HT behavioral syndrome. Pharmacol. Biochem. Behav. 24, 1513 - 1519 (1986)

29 Bockaert, J., Dumuis, A., Bouhelal, R., Sebben, M. and Cory, R.: Piperazine derivatives including the putative anxiolytic drugs, buspirone and ipsapirone, are agonists at $5-\mathrm{HT}_{1 \mathrm{~A}}$ receptors negatively coupled with adenylate cyclase in hippocampal neurons. Naunyn Schmiedebergs Arch. Pharmacol. 335, $588-.592(1987)$

30 Moser, P., Hibert, M., Middlemiss, D.N., Mir, A.K., Tricklebank, M.D. and Fozard, J.R.: Effects of MDL73005EF in animal models predictive of anxiolytic activity. Br. J. Pharmacol. 93, Supp. 3P (1988)

31 Engel, J.A., Hjorth, S., Svensson, K., Carlsson, A. and Liljequist, S.: Anticonflict effect of the putative serotonin receptor agonist 8-hydroxy-2(di-n-propylamino)tetralin (8-OH-DPAT). Eur. J. Pharmacol. 105, 365-368 (1984) 